\title{
Sobre a atualidade dos estudos literários hoje
}

\author{
Por Fabio Akcelrud Durão
}

Quando a Paula me convidou para vir falar nessa mesa sobre filosofia e arte como resistência, e isso em um colóquio sobre "Filosofia, arte e educação" pensei que esse seria uma ocasião delicada. Eu percebi logo que, é claro, a Paula me dava uma "deixa" para falar daquele conceito fundamental da filosofia alemã, o conceito de Bildung, que como termo filosófico-educacional se prestaria muito bem para descrever uma resistência possível diante da truculência da indústria cultural. Mas em português Bildung gera uma interessante confusão. Se falamos "formação de professores, de motoristas, de cidadãos" etc. temos uma coisa em mente, que em alemão poderia ser traduzido como Erziehung mas quando dizemos "formação" sem um adjetivo para modificar o substantivo, estamos no campo da Bildung. Pois bem, usar esse conceito de forma direta, imediata, hoje, é algo muito problemático. Isso por causa do seguinte: os conceitos da história da filosofia não estão todos disponíveis para quem quer que queira utilizá-los, a qualquer momento que seja. Existem aqueles que, com o passar do tempo vão envelhecendo e perdem sua relevância, sua eficácia, a capacidade de serem usados para a abordagem de problemas vivos e urgentes. Eu gostaria de propor a seguinte hipótese para começar a discussão, uma hipótese que não deixa de ser uma provocação: a de que o conceito de Bildung, de formação, está morto. Isso pode verificado, no próprio alemão, pelo declínio mais óbvio de palavras como Beruf, profissão. Dentro dela se pode ouvir o rufen, chamar, que nos faz lembrar algo de transcendente na prática de um ofício. Se há um chamado, quem chama? De onde vem a voz que chama? Mais ainda, lembrem-se que vários sobrenomes, uma das coisas que mais define nossa individualidade, os Schmidt, ou Smith, ou Ferreira, vêm de profissões. É interessante perceber que as discussões urgentes, hoje, na Alemanha (que tem um índice de desemprego assustador), não se referem de forma alguma a Beruf, tudo que se ouve é Arbeitsplätze ou Jobs (a palavra inglesa já foi normalmente incorporada ao alemão), que querem dizer "emprego". Os políticos falam que se deve criar novos Jobs, que não sei quantos Arbeitsplätze são necessários para o aliviamento da crise social etc. A mesma coisa acontece em inglês com uma palavra bem velha, calling, para designar a profissão. Consultando o OED (Oxford English Dictionary) encontramos o seguinte conjunto de sentidos:

I 1. The action of CALL; II 2, (An inward conviction of) divine prompting to salvation or to serve God (with reference to the Christian ministry with mixture of sense 4); a strong impulse towards a course of action as the right thing to do; (a) vocation. Middle English $\nmid 3$ Station in life; rank. 4. An occupation, a profession, a trade. (1)

Em português se pode ouvir um eco disso em vocação, que remete ao verbo vocare no latim, que quer dizer chamar, convocar. Em todos esses casos há uma idéia de que a estrutura do mundo é fixa, e de que cada um de nós tem um lugar já marcado na organização das coisas. Eu não preciso lembrar a origem religiosa disso. A primeira referência de quem chama é Deus; é ele que diria que alguém é um Smith (ferreiro), ou um Baker (padeiro), ou ainda um Cook (cozinheiro). Surge 
daí uma visão fechada do universo, onde cada um desempenha o papel de seus pais, e de acordo com sua posição ou camada social. O Job não é nada disso. Ele significa simplesmente "ocupação," a disponibilidade do indivíduo para uma tarefa que possa ser levada a cabo em troca de dinheiro. Se o indivíduo tem vocação para essa atividade específica não vem ao caso. Pelo contrário, implicito na palavra Job está a sua fungibilidade e possível curta duração.

É importante chamar a atenção que nesses opostos há coisas boas e ruins misturadas. Na idéia de vocação e ofício não há desemprego e existe a implicação de uma comunidade e a proteção que ela traz. Mas tudo isso acontece junto com uma grande falta de liberdade. Se algum "Ferreira" deseja fazer outra coisa que não ferrar cavalos sua vida vai ficar muito difícil. Com o emprego ocorre o contrário. A liberdade aqui é total: você pode fazer o que bem entender (contanto é claro que alguém lhe pague), mas em contrapartida nada está garantido, tudo é incerto $e$ transitório. É interessante salientar que o problema de se escolher uma profissão, hoje, vem disso. Ele seria incompreensível na Idade Média.

Pois bem, tudo isso tem implicações diretas para o tema da formação. Quem usa o conceito de Bildung como se ele estivesse disponível, como se ele pudesse ser usado agora, vai estar comentendo um erro sério, um erro que na área de Letras é muito fácil de ser cometido, e que se refere à cegueira em relação ao novo. Por exemplo, na própria gramática. Todos sabemos que é "errado" dizer-se "eu vi ela" ou "os político é tudo corrupto," e no entanto todos nós, repito, todos nós fazemos uso de estruturas sintáticas como essas em nosso dia-a-dia. É só que não estamos conscientes disso. Diga-se de passagem que não há nada de errado em se falar "errado." O certo da gramática tradicional, da gramática normativa, não é nada mais, nada menos, do que a racionalização de um uso histórico. Há uma série de regras que, quando não são apresentadas meramente como regras a ser decoradas, mas são justificadas semanticamente, não têm uma razão de ser intrínseca. Deve-se chamar à atenção que o erro também pode ser racionalizado semanticamente. Quando se diz "os político é tudo corrupto" a forma de plural está lá, no artigo. Não há necessidade de ser repetida em "os políticos são todos corruptos." Poder-se-ia muito bem dizer, então, que a forma "errada" é mais sintética e econômica do que a "correta," talvez até mesmo mais elegante. Pois bem, qualquer abordagem da questão da formação, tem assim que reconhecer a natureza eminentemente antiquada dessa problemática. Daí a minha tese, de que o problema da Bildung não tem nenhuma atualidade hoje. Tudo aquilo que a formação indica (conhecimento, uma subjetividade forte para poder discernir e criticar, instituições capazes de transmitir uma tradição educativa viva) - tudo isso já está há muito tempo fora de questão, morto. E só não vê isso quem não quer, ou não tem coragem.

Agora já posso apresentar a tese que eu gostaria de defender a respeito dos estudos literários, da sua relevância e utilidade, ou de acordo com o tema do colóquio, a resistência que podem exibir. Essa tese é bem simples; em poucas palavras, ela é a seguinte: a literatura, hoje, não tem relevância nenhuma, não tem utilidade nenhuma, não pode esboçar nenhum tipo de resistência. Eu sei que essa é uma formulação polêmica e talvez um pouco exagerada, além de ser 
desentusiasmadora para os estudantes. Mas ela corresponde a uma verdade que deve ser enunciada, e que tem que ser levada em consideração para que possamos, a partir dela, vislumbrar algo de interessante.

Para mostrar que a literatura não tem função nenhuma, nem mesmo a da resistência, vale a pena nos debruçarmos sobre o papel normalmente conferido à literatura. Tradicionalmente, sempre se disse que a literatura era uma fonte importante de divulgação e consolidação de valores morais positivos, que ela ajudaria a formar indivíduos bons. Ora, não se precisa ter lido muito para poder perceber que esse argumento de forma alguma se sustenta. Não se trata apenas do fato de que autores hoje canônicos apresentam um código moral no mínimo questionável (como Sade e Malebranche, os exemplos mais óbvios), mas também de que, quando lemos autores bonzinhos demais, ou pelo menos como se eles assim o fossem, eles ficam chatos. Interprete Dom Casmurro com valores rígidos e o romance se cala na sua frente. Se Capitu for considerada adúltera e simplesmente má, ou se Bentinho for considerado como paranóico e simplemente doente, o texto se empobrece e fica parecendo uma novela das oito. Um outro exemplo: o Satã do Paraíso Perdido de John Milton. Até o século XIX ele sempre foi lido literalmente, como um personagem que incorporava o Mal absoluto e se recusava a obedecer e reconhecer seu Criador. Foi apenas com o romantismo que surgiu aquela interpretação, hoje tão em voga, de se considerar Satã como representando a figura do poeta, como ele mesmo um criador que pretende construir um mundo a partir de si próprio. É importante enfatizar que esse movimento, essa relativização da moral, foi um ganho enorme para a literatura, porque ela fez parte de uma dinâmica de autonomização da arte. Ou seja, você agora, quer dizer, desde meados do século XIX, pode ler o Paraíso Perdido colocando em parênteses questões teológicas, pois elas não se impõem mais como um a priori, como algo que preceda a leitura. Diga-se de passagem que esse processo faz com que as novas interpretações teologizantes se tornem muito mais interessantes, porque elas têm que se confrontar com essa liberdade de valores. Em outras palavras, elas têm que provar, dentro da imanência do texto, que Deus é melhor que Satã. Com isso podemos começar a perceber que, seguindo de forma paralela à autonomização da literatura está a sua perda de função. O Paraíso Perdido não mais pode ser usado, por exemplo, dentro de um sermão ou como parte de uma discussão teológica. Melhor dizendo: é possível fazê-lo, mas assim estaríamos trantando o texto como alguma outra coisa e não como uma obra literária.

Mas eu estou me adiantando demais. Eu queria voltar e abordar um segundo argumento a respeito dos valores na literatura. Alguém poderia dizer que a representação do Mal não é em si má, que descrevê-lo e conhecê-lo não é sinônimo de praticá-lo; isso seria, pelo contrário, uma forma para melhor lidarmos com ele. Esse argumento também é histórico, e também surgiu no século XIX, notadamente na crítica shakespeariana. A variedade dos personagens de Shakespeare, dizia-se, representava a totalidade dos tipos humanos e exibia todas as características que nos fazem seres humanos. Lá teríamos o espectro completo dos tipos psicológicos, de caráter, de qualidades e defeitos, desde o mais nobre e o mais sublime até o mais vil e desprezível. Dentro dessa visão, os personagens 
malévolos, como Yago ou Edmund, teriam um papel fundamental para o enriquecimento da fauna humana de Shakespeare. É claro, essa idéia pode ser extendida a vários outros autores como Dickens e Balzac, mas ela encontra obstáculos sérios na literatura moderna. O que se ganha ao ler Proust, Kafka, Joyce, ou Musil com essas lentes? O problema aqui é que considerações morais, de qualquer espécie que sejam, levam a uma personificação, a uma antropologização da leitura, enquanto que a própria antropologização é um dos inimigos principais da literatura moderna. Mais ainda, até mesmo aquelas obras que parecem tão bem se adequar ao humano apresentam outras faces, que a obsessão antropológica apaga. Em Shakespeare, por exemplo, o homem não está separado de uma metafísica da natureza; em Macbeth, a noite na qual o Rei Duncan é assassinado "has been unruly. Where we lay,/ Our chimneys were blown down, and, as they say,/ Lamentings heard i'the air, strange screams of death,/ And prophesying, with accents terrible,/ Of dire combustion and confused events/ New-hatched to the woeful time". (II.3. 51-56)(2). Essa metafísica da natureza cerceia, em grande parte, a liberdade do indivíduo, além de nos ser, hoje, completamente estranha. Por outro lado, a crítica às leituras humanistas de Shakespeare já vem sendo feita há pelo menos vinte anos nos países de língua inglesa, e agora leva em consideração, não o supra-humano, mas o intra-humano. Já se tornou um lugar comum acadêmico se denunciar o adjetivo "humano" como um termo ideológico que oculta relações sociais determinadas de opressão de sexo, de classe e de raça. $\mathrm{O}$ "Homem", diz-se, não existe, é uma abstração que impede que se pense a diferença. Esse argumento, que se vê repetido ad nauseam em livros e revistas de crítica literária, em congressos e na sala de aula, não deixa de apresentar seus problemas, mas para fins de desmascarar ou desmistificar uma certa crítica tradicional ele cumpre um papel importante.

O papel de educação moral não foi o único atribuído à literatura. Misturado com ele, mas dentro de um horizonte completamente distinto, havia uma função política importante. Ao construir monumentos culturais, a crítica literária e suas instituições contribuiam para a normativização da língua, distinguindo o certo do errado, $e$ para uma regulamentação das temáticas narrativas, do imaginário ficcional. Seu principal objetivo do ponto de vista político era um processo de homogenização $e$ de unidade que facilitasse o processo de formação de nações. Não é à toa que, ainda hoje, quando aprendemos e ensinamos literatura, isso se dá sob o pano de fundo de nacionalidades: literatura inglesa, literatura norte-americana (que no fundo quer dizer "dos Estados Unidos," daí eu preferir o adjetivo "estadudinense"), literatura alemã etc. Não é à toa, também, que a obra-mestra da crítica literária brasileira seja A Formação da Literatura Brasileira do Antonio Candido, justamente por levar essa temática a sério e com rigor admirável. Ora, a questão a respeito do papel das nações hoje, como se sabe, tem sido muito debatido. Há vários pensadores que decretaram seu fim por causa da tão discutida globalização. Segundo eles, em vista do enorme poder dos fluxos de capitais, os países teriam sua liberdade de ação cerceada e os projetos nacionais perderiam, conseqüentemente, qualquer razão de ser. Eu não compartilho dessa visão de forma alguma, mas concordo que a literatura não desempenha atualmente nenhum papel político. Não porque ela não o queira, mas simplesmente porque seu efeito, sua área de ação, é muito limitada. Parem um pouco para pensar em 
quem vocês conhecem que leia literatura, que tenha o hábito de ler, inclusive obras difíceis, sem ter nenhum vínculo profissional com ela, sem ser professor ou estudante. Eu diria que esse número é reduzidíssimo, principalmente quando o colocamos lado-a-lado de outros meios de representação. Quem tem função política, hoje, quem pode formar e mudar opiniões, servir de referência para debates e para denotar movimentos, quem pode realmente resistir ao sistema não é mais a literatura, mas o cinema, a internet e, acima de tudo, a televisão. Então, para resumir: mesmo que o papel de definição de uma identidade nacional não esteja fora da pauta (o Fredric Jameson tem até uma hipótese radical a esse respeito, pois ele defende que toda produção ficcional dos países periféricos involve alegorias nacionais), o poder da literatura fica muito diminuido quando diante dos outros media, esses, sim, socialmente relevantes.

Disso também deriva a total irrelevância da literatura de um ponto de vista econômico. Quem lida com ensino sabe que se não fossem as instituições oficiais, a universidade e o colégio, ninguém mais publicaria livros que se pudesse conceituar de literatura. E mesmo assim, a movimentação de dinheiro envolvida na circulação de obras literárias (e aqui excluo toda a produção de massa dos bestsellers como Sidney Sheldon e o vergonhosamente imortal Paulo Coelho) é irrisólia se comparada, de novo, com o cinema ou a TV ou a música de massa. Em relação a isso, permitam-me uma breve digressão. A irrelevância econômica da literatura é o motivo principal porque não me sinto confortável com críticas ideológicas e denunciatórias das obras, tal como mencionei agora há pouco. Nos Estados Unidos já há algum tempo está na moda interpretar-se um dado autor canônico, por exemplo o Herman Melville, para mostrar como sua escrita não está isenta de aspectos racistas, sexistas e de classe. Lê-se assim com o intuito de se desmascarar, desbancar as grandes obras do cânone ocidental. O que sempre penso é: "muito bem, está provado que o Faulkner era racista. Mas e daí?" Quem se interessa com isso, o que se ganha com isso, além do fato de que o autor da análise conseguiu publicar um artigo? Pierre Bourdieu tem esse conceito do capital simbólico; eu diria que na literatura strictu sensu, como sua circulação é ínfima, ela acaba só envolvendo um grupo muito reduzido de connoisseurs ou experts. Vale muito mais a pena, ao invés de se deixar ofuscar pelas limitações de uma obra, averiguar como que elas contribuem para sua economia interna, qual a produção de sentido que geram.

Mas voltando para a nossa linha de argumentação: eu estou tentando provar que a literatura não serve para nada. Ela não tem utilidade moral, nem política, nem econômica. Mas vocês poderiam dizer: "e de um ponto de vista psicológico, a literatura não nos proporciona um prazer que no fundo tem uma validade? Ela não contribuiria, nem que fosse só um pouco, para nossa saúde mental?" Para responder a essa objeção seria necessário repetir o que acabei de dizer: quem realmente vai ler literatura motivado por uma vontade de prazer, sem qualquer relação com dever de casa, com prova ou monografia? Diga-se de passagem, até os profissionais do ramo, como muitos de vocês são ou serão, não conseguem ter uma relação de puro prazer com um romance, peça ou poema. Aqui só posso falar por mim, mas acho que minha experiência é generalizável: quando eu estou lendo alguma coisa, mesmo que não seja para um curso, mesmo que esteja desvinculado 
de todas as minhas atividades profissionais - digamos, nas férias, em Poços de Caldas - eu sempre me vejo atento para passagens interessantes e citáveis, acabo sempre estabelecendo paralelos, comparando e julgando. Em suma: não é mais possível ler sem interpretar. Aquele tipo de prazer de leitura, completamente descompromissado, que eu tinha quando era adolescente, é agora para mim uma impossibilidade. Mas o prazer imediato da leitura também é posto em cheque pela própria literatura moderna. Um livro como o Ulisses, do Joyce, é mais estudado do que lido; ou melhor, você só pode realmente lê-lo depois de estudá-lo. O prazer só pode vir, assim, depois de muito esforço, incerteza e até frustração; ele é um tipo de sentimento muito diferente daquilo que estamos acostumados chamar de prazer, aquela gratificação imediata e desconcentrada diante de coisas que não exigem muito de nós. Em outras palavras, o prazer verdadeiramente literário não pode ser separado do trabalho do leitor. Mas aqui alguém poderia perguntar: "mas por que se deveria trabalhar de graça? Se vou ter que gastar tempo e atenção, se vou ter que me cansar, para não ganhar nada, por que deveria fazê-lo? Por que não direcionar minhas energias para alguma coisa que me dê algo em troca?" A resposta para essa pergunta é a idéia principal que eu gostaria de abordar nessa palestra.

Mas antes de fazer isso ainda falta lidar com um último argumento, que agora se refere, não mais à moral, política, economia, nem psicologia, mas à ciência. Poderse-ia, de fato, defender que a função da literatura está ligada ao seu poder cognitivo, ao quanto ela permite que se adquira conhecimento. Eis aqui um campo mais difícil para se contra-argumentar. Pois quem negaria que há algo a se aprender no confronto com obras literárias? Vejamos, porém, com calma o que está em jogo aqui. Se a literatura deve poder fornecer um tipo de conhecimento, ou ele é específico a ela, ou comum a outras práticas de linguagem ou atividades sociais. Ora, para ser realmente um tipo de saber forte, que valha a pena o esforço, ele deve ser exclusivo à literatura. Há mais ou menos oitenta anos atrás os formalistas russos desenvolveram uma teoria interessante a esse respeito. Em um ensaio hoje canônico da teoria literária, "A arte como procedimento," Viktor Schklovski nos diz que aquilo que define a literatura é ao mesmo tempo sua função, pois a literatura seria um sistemático desvio da linguagem comum e seu papel seria o de desfamiliarizar a linguagem. Isso não quer dizer que as obras literárias tenham sempre que ser eruditas ou que tenham que fazer uso de uma linguagem rebuscada; se o normal, o corriqueiro em uma determinada situação é o rebuscado, então a literatura será simples. O importante no argumento do Schklovski é que, ao desfamiliarizar a linguagem, aquilo que nos parecia transparente e dado, um instrumento para fins diferentes de si próprio, agora se apresenta como visível e vivenciável. Com a teoria da desfamiliarização da linguagem nos damos conta do ser da língua, daquilo que ela tem que só pertence a ela mesma.

Não é à toa, como muitos de vocês devem saber, que o formalismo russo desembocou no estruturalismo com uma vontade de ciência que lhe era própria. Se pararmos para pensar, o ensaio "A arte como procedimento" não considera a arte como um campo autárquico, que tem ingerência sob si própria, mas ela tem sua definição subordinada, ou pelo menos misturada, com seu papel ou uso. Ou 
seja, para percebermos o ser da linguagem não precisamos das obras literárias. Os lingüistas podem fazer isso para nós; eles podem nos mostrar como línguas diferentes recortam o mundo de forma diferente, como, ao falar inglês, habitamos um universo diverso do nosso do dia-a-dia em português. Daí o fato de nunca aprendermos uma língua estrangeira, pois quando a aprendemos acabamos reaprendendo a nossa própria, verificando como expressões corriqueiras em nosso idoma se tornam metáforas engenhosas em outro. Como vocês sabem, o exemplo clássico que a lingüística nos fornece é o do arco-íris, que do ponto de vista físico é um degradê perfeito, e que assim precisa ser recortado pelas diversas línguas. Em inglês há seis cores, em português sete, e numa língua africana três. ( $\mathrm{O}$ exemplo que eu mesmo queria dar, que me veio à mente outro dia é o do boi, cuja forma de corte varia de língua para língua.)

Mas, na verdade, nem precisamos recorrer a línguas estrangeiras para ver como a linguagem abriga o diferente. Se olharmos com cuidado, e a língüística já há muito tempo vem chamando a atenção para isso, veremos como a língua varia das formas mais diversas. Ela varia conforme o lugar do falante (seu dialeto), sua idade, seu sexo, sua posição social, e o grupo profissional a que faz parte. No limite, há a idéia de idioleto, aquelas preferências lingüísticas, ou vícios de linguagem que só eu tenho, que são específicos a mim. E se nós quisermos realmente ser radicais podemos pensar na singularidade do aparelho fonético de cada um de nós, o formato da boca e da arcada dentária, da língua, dos lábios, o tamanho das cordas vocais, tudo isso que faz com que a voz de cada um de nós seja única no mundo; daí a possibilidade de se usar aparelhos de reconhecimento de voz como meios de se comprovar a identidade de alguém.

Como vocês podem ver, nós acabamos desembocando na Física e na Anatomia, ciências que estão muito distantes da literatura e que na verdade são seu verdadeiro oposto. Eu diria, então, que, mesmo que o aspecto cognitivo da literatura possa ser inegável, quando o colocamos como seu traço mais importante, sua característica mais determinante, surge a suspeita de que o conhecimento que é obtido poderia muito mais facilmente ser adquirido de outra forma, ao recorrermos a disciplinas específicas, como a psicologia, a sociologia ou a antropologia. Reitero então a minha tese: a literatura, hoje, não tem função, uso, ou relevância alguma, e como tal não pode ser instrumento de resistência, nem político, nem social, nem educacional, nem o que quer que seja. Mas isso quer dizer que devemos parar de lê-la? A resposta é um grande e contundente Não! Muito pelo contrário. É justamente pela falta de utilidade que a literatura se tornou algo fundamental para nós nesse começo de século.

Para percebermos a importância de alguma coisa que não serve para nada, é preciso refletirmos sobre o contrário, ou seja, sobre o fato de que, hoje, tudo tem que servir para alguma coisa. Alguns de vocês já devem ter passado por isso; mas comigo, quando eu fazia a faculdade lá na Federal do Rio de Janeiro, eu, que era homem, branco, e de classe média sólida, várias vezes as pessoas me perguntavam: mas por que você faz Letras? A mesma coisa poderia ter acontecido se eu fizesse Educação. Nessa pergunta estava implícito, além da crença de que a literatura era coisa de mulher, a opinião de que havia algo de desperdício para um 
rapaz de classe média, que vinha de um colégio de prestígio e que tinha muito boas notas, fazer Letras e não algo mais útil (que daria também mais dinheiro) como Engenharia, Medicina ou Direito. Mas então vem o estalo. Por que é que tudo tem que servir para alguma coisa? Que tipo de mentalidade é essa que quer que tudo tenha uma utilidade? Que mundo é esse no qual tudo tem de estar ligado à reprodução imediata do dia-a-dia? Muito possivelmente me seria respondido que essa fome de utilidade tem limites, que ela só se refere à vida profissional e que não se aplica às horas vagas, ao tempo do lazer. O problema nesse caso é duplo: em primeiro lugar há a pressuposição de uma divisão que já está tão entranhada nas nossas vidas, que nem percebemos que ela é histórica e que poderia ser diferente. Há aqui a equação trabalho/subsistência, por um lado, e tempo livre/prazer, por outro. Mas e quando isso não é assim? Como você lida com alguém que realmente gosta daquilo que faz? A representação dos cientistas na cultura de massa (nos desenhos animados, filmes e revistas em quadrinhos) como sendo um ser estranho, excêntrico, que pode até dar um pouco de medo, vem exatamente disso. Podemos ler isso que há de dissonante, na representação do cientista, como uma defesa da sociedade em relação a essa pergunta: como lidar com alguém que trabalha por que quer? Que não precisa ir toda sexta e sábado à noite tomar cerveja, que não tem a necessidade de pular carnaval todo ano, mas se mistura a tal ponto com aquilo que faz, que não mais pode se separar disso? Vocês podem imaginar o que aconteceria se todos exigissem isso, que todo trabalho fosse gratificante... Por isso é necessário representar o cientista como um tipo esquisito, e anti-social, com o qual não se deve ter muita empatia.

Mas há também um segundo problema. Mesmo que aceitemos a divisão entre trabalho e lazer, podemos nos perguntar: será que o que existe é realmente a diversão? Se pararmos para pensar, não é necessária muita inteligência para ver que há uma indústria do tempo livre, que é uma das principais áreas do setor de serviços. Há apenas uma inversão de função: enquanto se trabalha se é um produtor, enquanto se diverte se é um consumidor. Compra-se mercadorias que são produzidas em massa e que são confeccionadas de forma a gerar o mesmo tipo de efeito. Quem tem coragem, se pergunta se realmente há prazer na massificação do comportamento, na homogenização do vestir, na codificação dos gestos, na estandardização do gosto etc.

Talvez eu possa reformular o que estou querendo dizer da seguinte forma: na nossa sociedade tudo tem que ser para-o-outro, nada pode ser em si e para si. Num livro que merecidamente já faz parte do cânone da teoria literária, o Mitologias, Roland Barthes sugere um modelo semiológico simples, que ele chama de mecanismo da conotação e que consiste em sobrepôr um novo signo, com seu significante e significado, ao significante de um signo já existente. Pois bem, isso que o Barthes descreveu, em 1957, como a forma da mitologia moderna só fez se enraizar e se fortalecer, de tal forma que ele permeia totalidade dos objetos com os quais lidamos hoje. Essa incapacidade de dissociar as coisas (as mercadorias) daquilo que elas dizem de si próprias (por exemplo, uma motocicleta e a idéia de liberdade) é exatamente o que eu quero dizer com o ser-para-o-outro. Isso significa a formação de um sistema de equivalências onde tudo pode ser trocado e onde tudo se relaciona com tudo o mais. Ora, a literatura não faz parte disso; ou melhor, 
a experiência da leitura impede isso. Mas alguém poderia perguntar: na literatura não há também um sistema de conotação, no sentido que Barthes deu ao termo? Os assim-chamados "grandes autores" não seriam exatamente isso, rótulos que tornam textos monumentos, patrimônios da herança cultural? Sem dúvida. Mas o meu argumento é que isso não tem nada a ver com a literatura. A idéia que as pessoas têm, por exemplo, do Shakespeare, aquele "Óh" que, para citar Kant, deveria seguir toda representação, toda idéia, que se tem do grande autor - isso é o que mais prejudica a leitura de um texto forte. Quando lemos de verdade esquecemos daquele que escreveu o texto, esquecemos que o texto é um "grande texto"; para falar a verdade, esquecemos até mesmo quem somos. Nós penetramos o mundo singular da obra e o habitamos, ficamos lá, fingindo que esse universo é de verdade. Ora, quem mora em algum lugar sabe que os adjetivos são empobrecedores. Vocês podem dizer São Carlos é muito íngrime, mas o quanto isso pode definir tudo aquilo que vivemos em São Carlos? A mesma coisa acontece com um texto literário. A ironia machadiana existe, mas achar que seus textos se resumem a ela é uma coisa muito limitadora. Ou seja, todo o mecanismo de associação que nós já tão intimamente conhecemos (e que em inglês fica tão claro com o adjetivo "cool", que já é bastante usado na Alemanha) - é justamente esse mecanismo que é desfeito na leitura. (Daí a complicação de se reduzir a literatura aos estilos de época.)

Mas surge então uma outra questão: não se pode adotar a mesma postura em relação a todos os objetos do mundo? Essa atitude diante de textos literários, de atenção, escuta, e criatividade, ela não poderia ser expandida para tudo? A princípio sim, mas temos que estar bem atentos àquilo que nos impede disso. $\mathrm{A}$ rapidez das mensagens e a repetição do mesmo são características que dificultam em muito, se não tornarem simplesmente impossível o ato de leitura. Ler um filme significa assisti-lo várias vezes, pará-lo, pular partes, congelar imagens para que detalhes possam ser observados... Tudo isso, que o livro permite com muita facilidade, parece anormal para a nossa relação no dia-a-dia com os signos e as mensagens que nos cercam. Eles nos atacam mais do que se oferecem para a leitura; ler tudo significaria parar o fluxo de linguagem do mundo, como naquelas cenas congeladas do Matrix, mas não para brigar com os outros, mas para se abrir para as coisas.

Mas o que há de mais estranho, e essa é a idéia com a qual eu queria acabar, é que quando você reconhece que a literatura é inútil, que seu papel é meramente negativo - como disse, o papel de jogar na cara que o mundo no qual vivemos não deixa espaço para o que quer simplesmente existir - quando você se reconcilia com essa idéia, então tudo aquilo todas aquelas funções que a literatura não tem passam a ficar valendo. A visibilidade de sistemas morais, a singularidade das experiências nacionais, o prazer no livre funcionamento das faculdades imaginativas, o conhecimento de mundo autônomos e autárquicos - tudo isso se torna disponível e relevante. Esse tipo esdrúxulo de lógica que eu estou tentando descrever talvez possa ser chamado de "lógica do canto de olho", ou "de soslaio." Com isso quero tentar nomear aqueles seres fugidios que só existem quando não estamos olhando diretamente para eles, pois assim que eles passam a ocupar o centro da visão, assim que são focalizados, eles desaparecem. Parece-me que é 
esse o caso da literatura. Quando vamos a ela querendo obter algo, exigindo que ela nos dê algo - inclusive um modelo de resistência ao existente - ela se recusa e insiste em ser só ela mesma; mas quando a aceitamos assim como ela é, nos submetemos àquilo que ela propõe, seus mundos com suas leis e sua disciplina própria, quando não pedimos nada, enão ela parece nos fornecer tudo, mas pela porta dos fundos, por assim dizer. Então ela fica sussurrando que as coisas podiam ser diferentes. Eu queria terminar deixando uma pergunta em suspenso; eu queria saber se essa lógica do canto de olho não mereceria um nome, que talvez seja o mais deturpado e violentado nos dias de hoje - se ela não estaria próxima do verdadeiramente poderíamos chamar de amor.

(1) 1. a ação de chamar; 2. (uma convicção interior de) uma injunção divina à salvação ou para servir a Deus (com referência ao sacerdócio cristão, misturandose com o sentido 4); um forte impulso para determinada ação acertada; (a) vocação. Inglês medieval. 3. Posição social; 4. uma ocupação, profissão.

(2) "foi selvagem. Onde estávamos, nossas chaminés foram derrubadas pelo vento, $e$, como dizem, lamentações ouvidas no ar, estranhos urros de morte, e profecias com intonações terríveis, de sinistras combustões e eventos indiscerníveis, recémchocados pelo penoso tempo." 